\title{
A NOTE ON THE ASYMPTOTIC PROPERTIES OF ORTHOGONAL POLYNOMIALS*
}

\author{
R. WILSON
}

Let $\psi(u)$ be a function non-decreasing in the interval $(0,1)$ such that all the moments

$$
c_{k}=\int_{0}^{1} u^{k} d \psi(u), \quad k=0,1,2, \cdots,
$$

exist, and let $c_{0}$ be positive. Then

$$
f(z) \equiv \int_{0}^{1} \frac{d \psi(u)}{z-u}=\sum_{r=0}^{\infty} \frac{c_{r}}{z^{r+1}}
$$

may be developed in a continued fraction of which the denominators of the successive approximants are the Tchebichef polynomials $Q_{n}(z), \dagger$ where

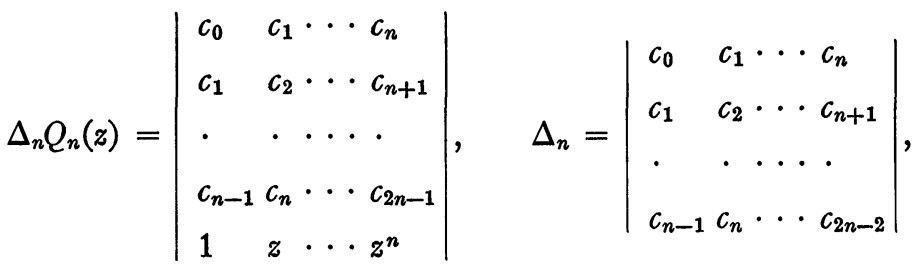

$$
\begin{aligned}
& n=0,1,2, \cdots ; \Delta_{0}=1 \text {. }
\end{aligned}
$$

The determinants $\Delta_{n}$ are positive unless $\psi(u)$ has only a finite number $\nu$ of points of increase, in which case $\Delta_{n}=0$ for $n>\nu$, and the continued fraction is terminating.

Shohat $\ddagger$ has shown that for an extensive class of moment functions (1) we have

$$
\left(\Delta_{n} / \Delta_{n+1}\right)^{1 / 2} \sim 4^{n},
$$

and that for all functions of this type satisfying (2) the recurrence

* Presented to the Society, February 29, 1936.

$\dagger$ J. Shohat, Théorie Gênérale des Polynomes Orthogonaux de Tchebichef, Paris, 1934, p. 12.

$\ddagger \mathrm{J}$. Chokhatte (Shohat), Sur le développement de l'intégrale $\int_{a}^{b}[p(y) /(x-y)] d y$ en fraction continue et sur les polynomes de Tchebycheff, Rendiconti del Circolo Matematico di Palermo, vol. 47 (1923), p. 32. 
relation connecting $Q_{n+2}(z), Q_{n+1}(z), Q_{n}(z)$ leads, as $n \rightarrow \infty$, to the characteristic equation

$$
\lambda^{2}-\lambda\left(z-\frac{1}{z}\right)+\frac{1}{16}=0 .^{*}
$$

From Poincaré's theorem $\dagger$ it follows that

$$
\lim _{n \rightarrow \infty} \frac{Q_{n+1}(z)}{Q_{n}(z)}
$$

exists and is equal to the root of larger modulus of (3) at all points $z$ outside the range $(0,1)$ for which the moduli of the roots of $(3)$ are equal. Shohat $\ddagger$ has further shown that over the range $(0,1)$

$$
\lim _{n \rightarrow \infty}\left(\Delta_{n} / \Delta_{n+1}\right)^{1 / 2} Q_{n}(z) /(1+\epsilon)^{n}=0
$$

for every positive $\epsilon$.

We prove the following theorem, which is a refinement of equation (4):

THEOREM 1. For the type of function considered

$$
\lim _{n \rightarrow \infty} \max _{0 \leqq z \leqq 1}\left|Q_{n}(z)\right|^{1 / n}=\frac{1}{4} .
$$

Following a theorem due to Perron, $\S$ if the limiting form of the difference equation has roots of equal moduli, then although

$$
\lim _{n \rightarrow \infty}\left\{Q_{n+1}(z) / Q_{n}(z)\right\}
$$

does not exist (in general),

$$
\limsup _{n \rightarrow \infty}\left|Q_{n}(z)\right|^{1 / n}
$$

exists and is equal to the common absolute value.

At every point of $(0,1)$ both roots of $(3)$ have the modulus $1 / 4$. Hence, at every point of $(0,1)$

$$
\limsup _{n \rightarrow \infty}\left|Q_{n}(z)\right|^{1 / n}=\frac{1}{4} \text {. }
$$

* Ibid., p. 43; see also Shohat, Théorie Générale . . , pp. 50-52.

$\dagger$ N. E. Nörlund, Differenzenrechnung, Berlin, 1924, pp. 300-305.

$\ddagger$ See Shohat, Sur le développement . . , p. 44; also Théorie Générale $\cdots$, p. 52.

$\S$ See Nörlund, p. 309. 
Let $T_{n}(z)$ be the unique polynomial of degree $n$, with coefficient of $z^{n}$ unity, whose maximum modulus over a given set $E$ is a minimum. Fekete* has proved that

$$
\lim _{n \rightarrow \infty} \max _{z \in E}\left|T_{n}(z)\right|^{1 / n}
$$

exists and is equal to the transfinite diameter of $E$.

It is well known that the transfinite diameter of the set $(0,1)$ is $1 / 4$. Hence, in this case,

$$
\lim _{n \rightarrow \infty} \max _{0 \leqq z \leqq 1}\left|T_{n}(z)\right|^{1 / n}=\frac{1}{4} .
$$

From the uniqueness of $T_{n}(z)$ and (5) and (6), the result follows. It is of interest to note that the $Q_{n}(z)$, derived from $f(z)$, possess on the one hand the orthogonal properties of Tchebichef polynomials and on the other hand the properties of $T$-polynomials over the set of singularities of $f(z)$.

Formula (2) easily leads to the following result, $\dagger$ obtained by Pólyał in the case of a more restricted type of moment function:

THEOREM 2. For the type of function considered

$$
\lim _{n \rightarrow \infty} \Delta^{1 / n(n-1)}=\frac{1}{4} .
$$

Theorems 1 and 2 are connected by the fact that each gives an expression § for the transfinite diameter of the set of singularities of the moment function in terms of the coefficients of (1). The fundamental quantities $Q_{n}(z)$ and $\Delta_{n}$ there occurring are invariant under the substitutions $z^{\prime}=z^{i \alpha}+c$, where $\alpha$ is real and $c$ is, in general, complex.

University College of Swansea,

WALES

* M. Fekete, Über die Verteilung der Wurzeln bei gewissen algebraischen Gleichungen mit ganzzahlingen Koeffizienten, Mathematische Zeitschrift, vol. 17 (1923), pp. 234-236.

$\dagger$ See J. Shohat, Théorie Générale . . , p. 57 for an associated theorem.

‡ G. P6lya, Über gewisse notwendige Determinantenkriterien fïr die Fortsetzbarkeit einer Potenzreihe, Mathematische Annalen, vol. 99 (1928), pp. 697-700.

$\S$ See M. Fekete, loc. cit. 